\title{
The LEP II RF Power Generation System
}

\author{
H. Frischholz \\ CERN, 1211 Geneva 23, Switzerland
}

\section{Abstract}

By means of the LEP II RF System the maximum circumferential accelerating voltage will be increased from $350 \mathrm{MV}$ at present to about $2000 \mathrm{MV}$, required for the $\mathrm{W}^{ \pm}$pair production at centre-of-mass energies around $180 \mathrm{GeV}$. The accelerating voltage will be provided by the existing copper RF cavity system (LEP Phase I) and 192 superconducting RF cavities to be installed in LEP by 1995 . These sc cavities will be powered by 12 high power klystrons via junction circulators and a WR 2300 waveguide power distribution system. Compared to the existing LEP I installation the output power of the LEP II klystrons has been increased from 1000 to $130 \mathrm{CW} \mathrm{KW}$ by making use of the full capacity of the HV power converters, rated at $100 \mathrm{KV}$ and $40 \mathrm{~A}$. Simultaneously, the power-handling capability of the junction circulators, when operated into a sliding short, could also be enhanced by the same amount. A description of the LEP II RF power generation system is given and, in particular, the improved performance of the high power klystrons, circulators, thyratron crowbars and hard tube modulators is discussed.

\section{INTRODUCTION}

For the $\mathrm{W}^{ \pm}$pair production in LEP a circumferential acceleration voltage of about $2000 \mathrm{MV}$ is required. This will be achieved by means of the LEP II RF system; i.e. in addition to the existing LEP I RF system [1] 12 more RF units will be installed in LEP by 1995. Each of these RF units consists of one high power klystron with its $\mathrm{HV}$ interface, a junction circulator, a WR 2300 waveguide power distribution system with four Magic Tee splitting stages, four cryostat-modules, each of which houses four superconducting RF cavities, and the associated controls and interlock electronics.

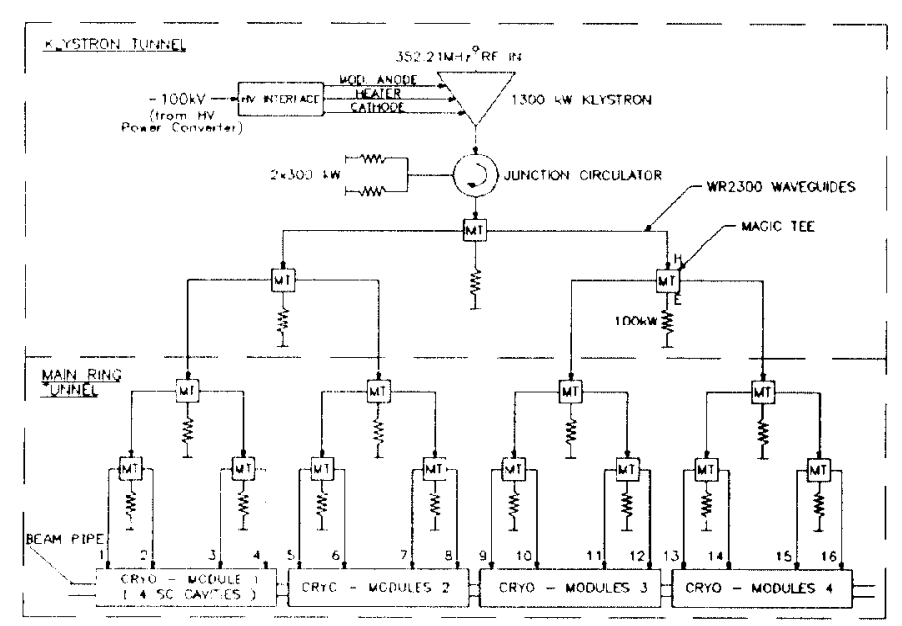

Fig. 1 - RF Power Distribution of a LEP II RF Unit
As can be seen from Fig. 1 the general layout of the LEP II RF units is very similar to that of LEP I. The main difference are the substitution of the copper cavities by superconducting ones and the need of only one klystron per RF unit.

At a specified sc cavity voltage gradient of $5 \mathrm{MV} / \mathrm{m}$ a total accelerating voltage of $136 \mathrm{MV}$ will be produced by one RF unit. At beam intensities of about $5 \mathrm{~mA}$ /beam the required RF power will be then $1300 \mathrm{KW}$.

By operating the klystrons at $100 \mathrm{KV}$ and $20 \mathrm{~A}$, the full capacity of the HV power converters, the rated klystron output power could be increased from 1000 to $1300 \mathrm{KW}$. Simultaneously the RF power handling capability of the circulators could also be increased to $1300 \mathrm{KW}$, even when the output signal is fully reflected at any RF phase angle.

The HV interface [2], consisting of a thyratron crowbar, a hard tube modulator and a $2 \mu \mathrm{F}$ smoothing capacitor, had to be adapted to the enhanced HV operating voltage. The main modification with respect to the original layout is the replacement of the 5-gap EEV-CX 1194B thyratron by the 8-gap model CX 2098B of the same firm and the controls and interlock electronics associated to it.

\section{GENERAL}

For compatibility and cost reasons the general layout of the LEP II RF units is very similar to that of a LEP I unit. Beside the substitution of the copper cavities by superconducting ones [3], the use of only one high power klystron with $\mathrm{HV}$ interface and one high power junction circulator, each with improved performance, only minor changes were required. In order to avoid cavity tuning errors, which can be caused by cross coupling of the fundamental RF signal between adjacent cavities [4], the isolation via the feeder lines had to be increased. Improved intercavity isolation is achieved by supplying the $100 \mathrm{KW}$ coaxial water loads, required for the Eport termination of the 12 Magic Tees of the two last power splitting stages (see Fig. 1), with saltwater. The substitution of demineralised water by doped water with a $\mathrm{NaC} \ell$ content of $1 \%$ decreases the reflection of the loads from -17 to $-28 \mathrm{~dB}$ and improves thus the fundamental signal isolation between adjacent cavities via the feeder lines from $-19 \mathrm{~dB}$ to $-26 \mathrm{~dB}$.

Another modification concerns the terminating load of the junction circulator. In case of beam loss the incident RF power is partly or fully reflected by the sc cavities, i.e. up to $1300 \mathrm{KW}$ of RF power will be diverted by the junction circulator into the terminating load at its port $\# 3$. Minor cavity tuning errors also result in high reflected power levels. For these reasons the port \#3 of the circulator is terminated via a specially developed waveguide-to-double coax transition with two $300 \mathrm{KW}$ coaxial loads. These loads, although limited to a continuous absorption of $2 \times 300 \mathrm{KW}$, are capable to absorb up to $1300 \mathrm{KW}$ for about 1 minute.

By April 1993 the klystrons, circulators, HV interfaces and waveguide components had been installed in four LEP II 
RF units, but only in one unit two cryo-modules $(8 \mathrm{sc}$ cavities) are in place. One of the four units is equipped with two klystrons and circulators, i.e. $8 \mathrm{sc}$ cavities will be powered by one klystron, in order to gain experience for a possible upgrade to two klystrons per 16 cavities (one klystron per 8 cavities, but one HV power converter for two klystrons) which might become necessary when the accumulated beam intensities in LEP would exceed $5 \mathrm{~mA} /$ beam. The HV power converters, which are of the same type as those for the LEP I RF systcm, have a ratcd capacity of $100 \mathrm{KV}$ and $40 \mathrm{~A} \mathrm{[5]} \mathrm{and} \mathrm{could} \mathrm{thus} \mathrm{cope} \mathrm{with} \mathrm{the} \mathrm{max.}$ $\mathrm{HV}$ power requirement of two klystrons.

\section{KLYSTRONS}

In 1990 a programme was launched with industry to increase the maximum klystron output power by making use of the rated capacity of the HV power converters. The programme resulted in a new series of high power klystrons with technical specifications, the main parameters of which are listed in table $\mathrm{I}$. The main feature of the klystron operation at $100 \mathrm{KV}$ and $20 \mathrm{~A}$ is the maximum output power achieved, namely $1300 \mathrm{KW}$; corresponding to a DC-to-RF conversion efficiency of $65 \%$ (see Fig. 2). This is to be compared with the LEP I klystron operation at $88 \mathrm{KV}$ and about $18 \mathrm{~A}$ where a maximum output power of $1000 \mathrm{KW}$ is achieved.

Due to the generation of relatively high accelerating voltages at low RF power the output of each klystron must be reduced drastically during beam accumulation at $20 \mathrm{GeV}$. Therefore, the specification calls for a minimum klystron beam current of $2.5 \mathrm{~A}$ at an operating voltage of $100 \mathrm{KV}$. The output power, which is exclusively controlled by the klystron's beam, is then below $1 \mathrm{KW}$. The focusing current settings must be such that they can remain unchanged when the beam current is varied between 2.5 and $20 \mathrm{~A}$.
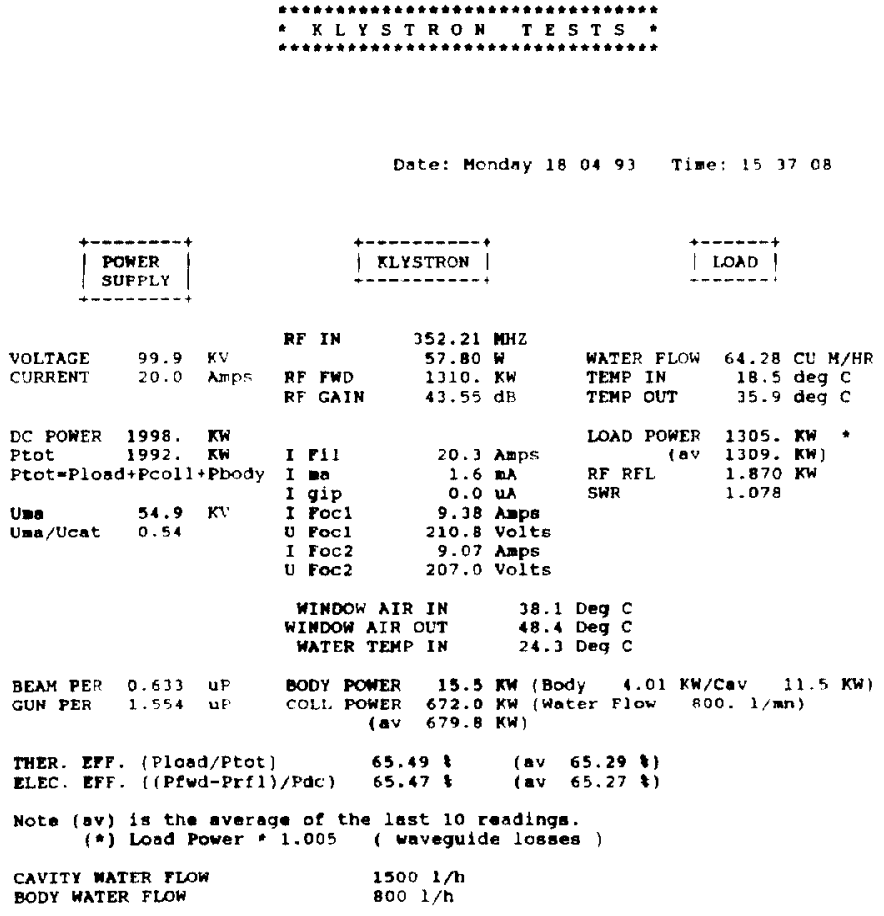

Fig. 2 : Computer Printout of a Klystron Acceptance Test (Sample)

\begin{tabular}{|l|c|}
\hline Rated Output Power & $1300 \mathrm{KW} \mathrm{cw}$ \\
\hline Operating Frequency (fo) & $352.21 \mathrm{MHz}$ \\
\hline-1 db Output Bandwidth & fo $\pm 500 \mathrm{KHz}$ \\
\hline DC-to-RF Conversion Efficiency & $65 \%$ \\
\hline RF-Input-to-Output Gain & $\geq 40 \mathrm{db}$ \\
\hline Max. Load VSWR & 1.2 \\
\hline DC Operating Voltage & $100 \mathrm{KV}$ \\
\hline DC Beam Current & $20 \mathrm{~A}$ \\
\hline Gun Perveance & $1.5 \mu \mathrm{AV}-1.5$ \\
\hline Body Dissipation & $\leq 30 \mathrm{KW}$ \\
\hline Focusing Coil Current & $\leq 12 \mathrm{~A}$ \\
\hline Modulation Anode Current & $\leq 5 \mathrm{~mA}$ \\
\hline Collector Dissipation Ability & $\geq 800 \mathrm{KW}$ \\
\hline
\end{tabular}

Table I : Main Electrical Klystron Parameters at Rated Output Power

\section{CIRCULATORS}

Contrary to the LEP copper cavities, at which the RF reflection depends very little on the beam intensity, the incident RF power is fully reflected by the strongly overcoupled sc cavities at the absence of beam. Therefore, the LEP II circulators are specified for $100 \%$ reflection, i.e. $P_{\text {forw }}=P_{\text {refl }}=1300 \mathrm{KW} \mathrm{cw}$. Prior to the installation in LEP each circulator is power tested at full reflection and any phase angle by terminating the output port with a sliding short and port \#3 with a $1500 \mathrm{KW}$ waveguide load (VSWR $\leq 1.05$ ). When at all RF phase angles of the reflected signal no arcs occur, and the input reflection $\left(S_{11}\right)$, isolation $\left(S_{12}\right)$ and insertion loss $\left(S_{21}\right)$ fulfil the specifications (Table II) the circulator is provisionally accepted. Since the insertion loss depends on the phase angle of the reflected signal the external magnetic field has to be adjusted accordingly by means of an electro-magnet [1] in order to obtain the specified values for isolation and input reflection. Prior to the high power test the specified values for the isolation $\left(\mathrm{S}_{12}\right)$ of -20 and $-10 \mathrm{~dB}$ within the bandwidth of fo $\pm 10 \mathrm{MHz}$ and fo $\pm 16 \mathrm{MHz}$ respectively are verified at signal generator power level. The high power behaviour is then simulated by the circulation of warm water in the ferrite cooling channels which increases the ferrite temperature to values as under high power operation conditions.

\begin{tabular}{|l|c|}
\hline Rated RF Powcr at Input Port & $1300 \mathrm{KW} \mathrm{cw}$ \\
\hline $\begin{array}{l}\text { Max. Reflected RF Power at Output Port } \\
\text { (at any RF phase angle with respect to } \\
\text { incident signal) }\end{array}$ & $1300 \mathrm{KW} \mathrm{cw}$ \\
\hline Operating Frequency (fo) & $352.21 \mathrm{MHz}$ \\
\hline $\begin{array}{l}\text { Output-to-Input-Port Isolation }\left(\mathrm{S}_{12}\right) \\
\text { a) at fo } \pm 10 \mathrm{MHz}\end{array}$ & $\leq-20 \mathrm{db}$ \\
b) at fo $\pm 16 \mathrm{MHz}$ & $\leq-10 \mathrm{db}$ \\
\hline Input Reflection $\left(\mathrm{S}_{11}\right)$ & $\leq-20 \mathrm{db}$ \\
\hline Insertion Loss $\left(\mathrm{S}_{21}\right)$ (at $\mathrm{P}_{\text {refl } ~}$ \& Porw $\left._{\text {for }}\right)$ & $\leq 0.1 \mathrm{db}$ \\
\hline
\end{tabular}

Table II : Main Y-Junction Circulator Parameters 
Circulators with clockwise and counterclock-wise RF power flow are required in the LEP II RF system. (6 of each). For reasons of compatibility the circulators must be made such that they can be used for both rotation modes by simply turning them by $180^{\circ}$ around their horizontal plane.

\section{HV INTERFACE}

The HV interface of a LEP II RF unit [6] comprises a commutator switch, a smoothing capacitor, a thyratron crowbar, a hard tube modulator, protection resistors and insulation transformers (see Fig. 3). Since the above mentioned components are immersed in oil they must be housed in a fire-proof bunker which is located in the klystron gallery. The high power klystron to be supplied with cathode, filament and modulation anode voltage is installed at a distance of about $20 \mathrm{~m}$ from this HV bunker whereas the distance to the HV power converter at the surface is about $500 \mathrm{~m}$.

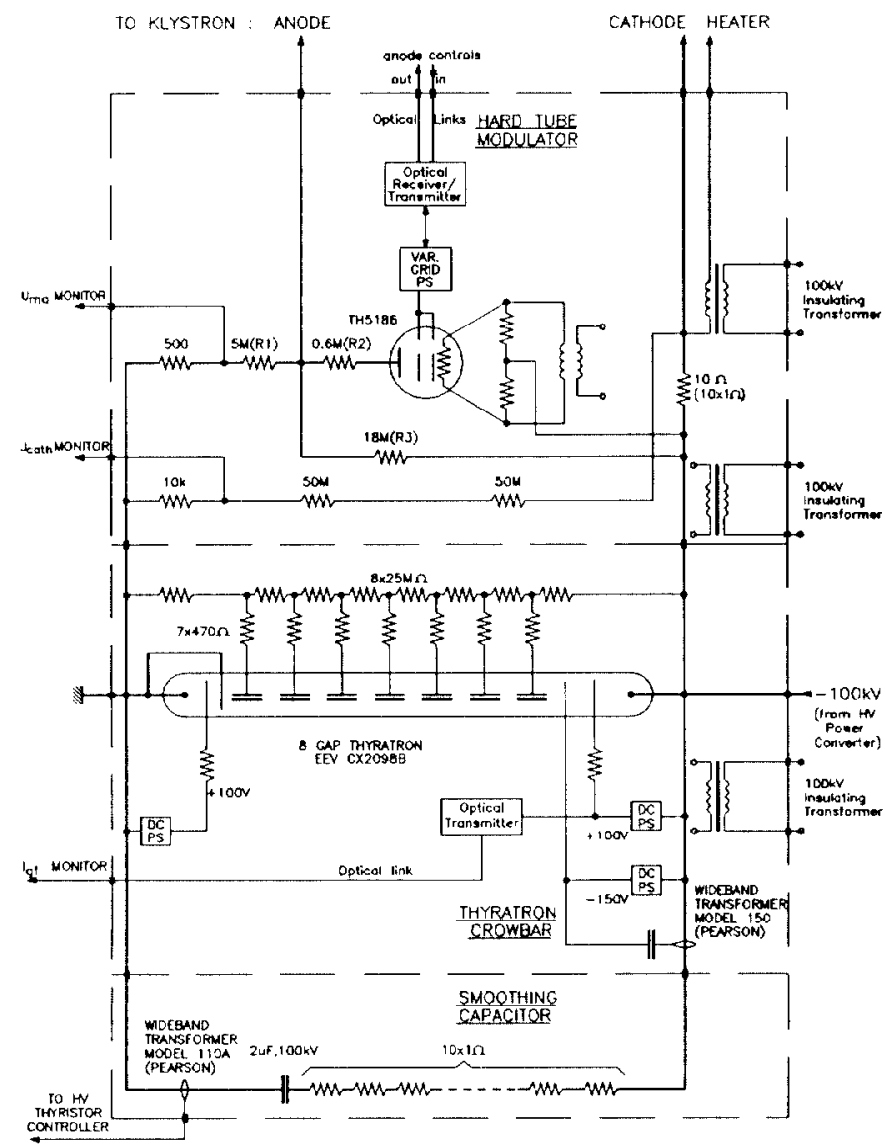

Fig. 3 : HV Interface of LEP II RF Unit

The higher klystron operating voltage does not necessitate the replacement of the $2 \mu \mathrm{F}$ smoothing capacitor including its current limiting ceramic resistor since its rated voltage is $100 \mathrm{KV}$ and a max. discharge current of $10000 \mathrm{~A}$, which occurs in the event of crowbar operation, is acceptable. A wideband current transformer is inserted in the low vollage line of the capacitor. Its output is connected to the thyristor control unit of the HV power converter. At a discharge current of about $500 \mathrm{~A}$ the thyristor will turn off the HV within $10 \mathrm{~ms}$.
However, the 5-gap, double ended thyratron CX 1194B in the crowbar tank had been replaced by the 8-gap model CX 2098B of the same firm. By lowering the voltage per gap to $12.5 \mathrm{KV}$ the reliability of the $\mathrm{HV}$ interface is expected to further improve. The electronic trigger circuit had been simplified to a commercially available wideband current transformer the output of which is connected to grid 2 of the thyratron via a ceramic capacitor. The wideband transformer with its incorporated integrator insures thyratron firing at discharge currents $\geq 500 \mathrm{~A}$. when the grid 2 biasing voltage is set to $-150 \mathrm{~V}$.

The cathode/grid 1 area is kept ionised by the $+100 \mathrm{~V}$ grid 1 biasing power supply. A current of about $25 \mathrm{~mA}$ is drawn, when the cathode is correctly heated, by which the readiness of the thyratron to act as a rapid protection device is indicated. This current is monitored and incorporated in the interlock system via an optical link (see Fig. 3).

The output power of the klystron is controlled by the modulator via the modulation anode voltage. The modulator comprises mainly HV power resistors and the HV tetrode TH 5186, which is suited for $100 \mathrm{KV}$ operation. Its two grids have been short-circuited and the tube acts thus as a triode, requiring only one grid biasing supply. The function of the tube is that of a variable high voltage resistor. By the resistors $R_{1}, R_{2}$ and $R_{3}$ the minimum and maximum modulation anode voltage and thus the klystron output power $(<1 \mathrm{KW}$ and $1300 \mathrm{KW}$ ) are determinated. The tube represents then either an infinite or a very small resistor value compared to those of the above mentioned HV resistors. By means of a variable grid supply which is controlled via an optical link the internal impedance of the tube can be varied between these two extremes.

An additional feature of the new resistive divider is the attractive possibility to achieve a maximum klystron output power of $1000 \mathrm{KW}$ when operated at $77 \mathrm{KV}$ only. This is to be compared with $700 \mathrm{KW}$ previously achievable. At the $77 \mathrm{KV}$ operating point the RF system has demonstrated proven reliability during the last years of LEP operation.

\section{ACKNOWLEDGEMENTS}

The author would like to thank P. Bricchi, J.P. Boitcux, B. Lambert, S. Livesley, G. Pecheur and G. Rochepeau for their valuable contribution to the development of the LEP II high power system and also E. Rugo, A. Simonini and W. Sunier for their contribution to the realisation, testing and building of much of the electronics and mechanical components. Thanks are also due to many other members of the SL-RFL Group.

\section{REFERENCES}

[ 1] H. Frischholz, Proc. 1989 IEEE Particle Accel. Conf., Chicago, p. 1131-1133.

[ 2] H. O'Hanlon, G. Pecheur, Proc, 1987 IEEE Particle Accel. Conf., Washington, p. 16191621.

[ 3] G. Cavallari et al, Proc. XVth International conf. on high energy Accel., HEACC ‘92, Hamburg, p. 694-695.

[ 4] G. Geschonke, private communications.

[ 5] P. Proudlock, H.W. Isch, Proc. 2nd EPAC 1990, Nice.

[ 6] H. Frischholz, G. Pecheur, "HV Interface for the LEP II RF System", to be published. 